\title{
Narrative medicine educational project to improve the care of patients with chronic obstructive pulmonary disease
}

\author{
Antonietta Cappuccio (1) ${ }^{1}$, Alessandro Sanduzzi Zamparelli², Massimo Verga ${ }^{3}$, \\ Stefano Nardini ${ }^{4}$, Alessandro Policreti ${ }^{5}$, Pasquale Alberto Porpiglia ${ }^{5}$, \\ Silvia Napolitano ${ }^{1}$ and Maria Giulia Marini ${ }^{1}$ on behalf of the Words of Breath \\ Group
}

Affiliations: ${ }^{1}$ Fondazione ISTUD, Milan, Italy. ${ }^{2}$ Dept of Clinical Medicine and Surgery, Section of Respiratory Disease, University Federico II, Naples, Italy. ${ }^{3}$ Antismoking Centre, ASST Santi Paolo e Carlo, Milan, Italy. ${ }^{4}$ Pulmonary and TB Unit, General Hospital, Vittorio Veneto, Italy. ${ }^{5}$ Medical Dept, Novartis Farma, Origgio, Italy.

Correspondence: Antonietta Cappuccio, Fondazione ISTUD, Piazza IV Novembre 7, 20124 Milan, Italy. E-mail: acappucciodistud.it

ABSTRACT Chronic obstructive pulmonary disease (COPD) is characterised by a progressive loss of pulmonary function. Often patients do not adhere to inhaled therapies and this leads clinicians to switch treatments in order to improve control of the symptoms. Narrative medicine is a useful approach that helps healthcare professionals to think over the doctor-patient relationship and how patients live with their disease. The aim of this training project was to teach pulmonologists the basics of narrative medicine: to carefully listen to patients and to practice reflective writing in their relationship with them.

Training on narrative medicine and parallel charts was provided through a webinar and a weekly newsletter.

Across 362 narratives, written by 74 Italian pulmonologists, $92 \%$ of patients had activity limitations at their first visit. The main factor influencing the effectiveness and adherence to therapy was a positive doctor-patient relationship; indeed, if such relationship is difficult, only $21 \%$ of patients are able to resume all their activities.

After learning the narrative approach, clinicians became aware of the need to spend more time listening to patients, to reflect through writing and to understand more deeply the motivations that lead people towards adherence to new therapies.

@ERSpublications

The experience of 79 Italian pulmonologists using the narrative medicine approach in COPD http://ow.ly/NfnY30jdEpS

Cite this article as: Cappuccio A, Sanduzzi Zamparelli A, Verga M, et al. Narrative medicine educational project to improve the care of patients with chronic obstructive pulmonary disease. ERJ Open Res 2018; 4: 00155-2017 [https://doi.org/10.1183/23120541.00155-2017].

Received: Dec 012017 | Accepted after revision: March 242018

Copyright $\odot$ ERS 2018. This article is open access and distributed under the terms of the Creative Commons Attribution Non-Commercial Licence 4.0. 


\section{Introduction}

\section{Disease characteristics and implications}

Chronic obstructive pulmonary disease (COPD) is the fourth leading cause of death in the world [1] and is expected to climb to third place by 2030. Smoking is the main risk factor [2]. It is estimated that in Italy approximately 2.6 million people have COPD [3], with a resulting significant economic burden [4].

COPD is a preventable and treatable chronic respiratory disease [5], whose high burden is related to delayed diagnoses [6,7], low adherence to therapy [8] and difficulties in quitting smoking [9].

The primary symptom of COPD is dyspnoea, or breathlessness, which is associated with poor quality of life and difficulty in performing even the simplest activities [10-12]. Studies suggest that COPD is often perceived by patients "not as a disease, but as a health problem" related to their lifestyle [13], often causing shame and isolation [14].

Although a definitive cure for COPD does not yet exist, the disease can be adequately controlled through therapy, especially if diagnosed at an early stage. However, adherence to treatment and changes in health behaviours (e.g. smoking) are extremely inadequate, with rates of $<50 \%$ in Europe and USA, which have detrimental effects on patients' quality of life and on progression of the disease [15-18].

Previous research, conducted by the ISTUD Foundation (Milan, Italy; www.istud.it), showed that positive doctor-patient relationships and good communication can improve patient compliance, with a beneficial impact on quality of life [19]. This research, which applied the narrative medicine approach, indicated the beneficial impact of this kind of education; therefore, we decided to develop a specific educational project.

\section{Parallel charts: a narrative medicine tool used to think over the doctor-patient relationship}

Narrative medicine is a patient-centred approach that leads to an understanding of how patients live with their disease through deeply empathic listening to their needs and emotions [20,21].

The parallel chart is a narrative medicine tool where professionals can freely express their feelings towards patients [22]. In other words, the parallel chart is a physician's narrative which allows them to think over the patient's story in detail, to understand the strengths and weaknesses of their relationship, while being able to decide if and with whom to share this narration [22].

Although many US and European medical schools offer narrative medicine courses in their learning programmes (e.g. "Impact of Early Implementation of Narrative Medicine Techniques on Patient Centered Attitudes of Medical Students"; ClinicalTrials.gov identifier NCT03041571), very little data is available on narrative medicine teaching and learning, and on its impact on clinical practice [23]. The educational projects driven by the ISTUD Foundation are based on Kolb's theory of adult experiential learning and this approach was adapted to this educational project in order to foster learning [24].

The aim of this educational project was to teach pulmonologists to carefully listen to their patients and to make them exercise the narrative medicine approach through writing parallel charts. The second objective was to understand the factors that influence the relationships between pulmonologists and patients with COPD, and how to foster positive relationships.

\section{Methods}

Participants and study design

From November 2016 to March 2017, 79 Italian pulmonologists participated in the project. The educational resources and the method of analysis were agreed upon by the Steering Committee of the project board, composed of pulmonologists and experts in narrative medicine research. Each physician was invited to attend a webinar on narrative medicine or to watch the recorded video of the lesson. After the lesson, each pulmonologist was given the assignment to experiment with reflective writing of at least five parallel charts in order to familiarise themselves with the practice of narrative medicine. All the pulmonologists received a weekly newsletter with research materials (e.g. articles and video on narrative medicine) and examples of parallel charts, which took around $10 \mathrm{~min}$ to read, and each month they received the online journal Chronicles of Narrative Medicine (www.medicinanarrativa.eu) with news and thoughts written by the ISTUD Foundation, readable in $30 \mathrm{~min}$. This newsletter represented the "concrete experience" stage described in Kolb's learning cycle [24]. Before taking part in the project, each pulmonologist signed a consent form describing the objectives and methods, and ensuring the total anonymity of the stories. The project was conducted in compliance with the Declaration of Helsinki.

In order to help the clinicians to overcome writer's block, the parallel chart included prompts that followed a semistructured narrative plot, representing a chronological series of events [25]. The parallel chart plot was designed and revised by the Steering Committee [26]. 
Clinicians had the choice to write the parallel chart with or without the prompts; however, to be eligible for the study, the personalised chart had to deal with a relationship of the physician with a COPD patient whom the pulmonologist had prescribed a change of therapy or a new therapy 3-6 months before the end of the project and a patient that they had seen at least twice during the project. Pulmonologists wrote the parallel chart after at least two visits and could choose to write it immediately after the visit or later, in the privacy of their own homes, which offered more time for an introspective reflection. There was no maximum or minimum length required for the narratives.

Narratives were collected through the SurveyGizmo online survey platform (www.surveygizmo.com); at the end of the survey period, raw and anonymous data were downloaded as an Excel spreadsheet (Microsoft, Redmond, WA, USA). All data were self-reported and submitted anonymously. In particular, anonymity was guaranteed by an automatic coding system that assigned a code to each participant in order to enter the platform. No patient-sensitive data were reported and parallel charts were collected as part of the educational practice in narrative medicine.

\section{Population size, data and text analysis}

Sociodemographic variables of pulmonologists were analysed with descriptive statistics (means, ranges and classes) and frequencies were reported as percentages.

The narratives, written in the local language (Italian), were analysed using the grounded theory approach for the qualitative interpretation of texts [27]. To reduce interpretation bias, analyses were conducted via triple-blind reading, by three independent researchers [28].

Narratives were also analysed through specific semantic evaluation software (NVivo version 10; QSR International, Doncaster, Australia) that assesses recurrent words and common synonyms to obtain clusters that were not previously predictable. In addition to the grounded theory approach, a thematic analysis was carried out in accordance with Kleinman's and Bury's classification $[29,30]$. From the parallel charts, three types of doctor-patient relationships were identified: 1) the easy relationship, where there is immediate sympathy between the patient and the pulmonologist; 2) the difficult relationship, where the physician feels discomfort in relating to the patient; and 3) the evolving relationship, which starts as difficult but changes to positive. The analyses of the narratives were reported both with the frequencies and extracts from the parallel charts translated into English.

\section{Results}

\section{Profile of the physicians}

79 Italian pulmonologists participated on a voluntary basis in this educational narrative medicine training, which was proposed by the ISTUD Foundation to more than 96 clinicians. They could choose from three dates to follow the 2-h live webinar; those who could not attend on any of the dates proposed watched a recording of the lesson and were then contacted by telephone by the teachers to check for any additional queries. 74 pulmonologists wrote parallel charts; they wrote an average of 4.9 parallel charts each, for a total of 367 narratives for 367 individuals living with COPD in Italy. Five narratives were excluded from the analysis, since they had not been completed.

The pulmonologists who took part in the project were mostly male (table 1), with a mean age of 52 years, which is consistent with the average age of Italian physicians [31]. Participants mainly came from the public healthcare sector and $86 \%$ of them specialised in respiratory diseases.

\section{The language of parallel charts}

Analysing the parallel charts in their entirety, $85 \%$ of the topics could be classified as "illness-centred" physician narratives. "Sickness" was mentioned together with "illness" in $26 \%$ of the parallel charts, and was mainly related to smoking and activity limitations due to the disease.

Consistent with Bury's classification [30], 42\% of the parallel charts were considered "core" physician narratives, while $42 \%$ were "contingent" stories, because of their brevity or lack of emotions described. 16 of the parallel charts were classified as "moral", because they contained judgements about patients; in this case, physicians used the tool to vent about unpleasant and difficult relationships, even while focusing on the life of their patients.

Analysing the characteristics of the clinicians that affect the style used to write the parallel charts, we noted that there was no sex difference; influencing factors were age, geographical origin and type of healthcare facility the clinician works in (table 2). 


\section{TABLE 1 Personal details and profile of the 74 physicians who wrote parallel charts}

$\begin{array}{lr}\text { Sex } & \\ \text { Female } & 42(31) \\ \text { Male } & 58(43) \\ \text { Age years } & 52(31-69) \\ \text { Professional years } & 23(5-40) \\ \text { Region of origin } & 45(33) \\ \quad \text { Northern Italy } & 27(20) \\ \text { Central Italy } & 28(21) \\ \text { Southern Italy } & 47(35) \\ \text { Work setting } & 41(30) \\ \text { Working in a hospital } & 9(7) \\ \text { Working in local public healthcare facilities } & 3(2) \\ \text { Working in a private clinic } & \\ \text { Working as a private practitioner } & 86(64) \\ \text { Specialisation } & 14(10) \\ \text { Respiratory diseases } & \\ \text { Internal medicine } & \end{array}$

\section{Narrative variables}

Pulmonologists had the chance to write parallel charts with no time or length limitations. As summarised in table 3, the type of narratives influenced the time spent writing and the narrative length. $74 \%$ of the "contingent" parallel charts were written using less than 2000 characters, while for $67 \%$ of "core" physician narratives pulmonologist used more than 2000 characters.

\section{Doctor-patient relationship in the parallel charts}

Here, we show how the narrative experience had an impact on the doctor-patient relationship, which was the goal of the educational project.

Physicians were encouraged, during the training phase, to ask their patient how the disease affected their life and what the patient's emotions were, in order to identify the motivations that could inspire patients to take care of themselves. Pulmonologists established easy relationships in $72 \%$ of "contingent" narratives and in $65 \%$ of "core" narratives, whereas in "moral" narratives just $26 \%$ of relationships started as easy.

\section{TABLE 2 Characteristics that influenced the narrative style chosen by pulmonologists}

\begin{tabular}{|c|c|c|c|}
\hline & $\begin{array}{l}\text { “Core" parallel } \\
\text { charts }\end{array}$ & $\begin{array}{l}\text { “Contingent” parallel } \\
\text { charts }\end{array}$ & $\begin{array}{l}\text { “Moral” parallel } \\
\text { charts }\end{array}$ \\
\hline Charts & 150 & 153 & 59 \\
\hline \multicolumn{4}{|l|}{ Region of origin } \\
\hline Northern Italy & $39(64)$ & $49(80)$ & $12(20)$ \\
\hline Central Italy & $46(45)$ & 32 (32) & $22(22)$ \\
\hline Southern Italy & $41(41)$ & $41(41)$ & $17(17)$ \\
\hline \multicolumn{4}{|l|}{ Work setting } \\
\hline Working in a hospital & $38(66)$ & $48(84)$ & $14(26)$ \\
\hline $\begin{array}{l}\text { Working in local public } \\
\text { healthcare facilities }\end{array}$ & $43(62)$ & $37(54)$ & $20(29)$ \\
\hline Working in a private clinic & $57(17)$ & 30 (9) & $13(4)$ \\
\hline Working as a private practitioner & $45(5)$ & $55(6)$ & $0(0)$ \\
\hline \multicolumn{4}{|l|}{ Age years } \\
\hline $30-39$ & $47(21)$ & $44(20)$ & $9(4)$ \\
\hline $40-49$ & $44(46)$ & $46(48)$ & $10(10)$ \\
\hline $50-59$ & $39(43)$ & $45(50)$ & $15(17)$ \\
\hline $60-69$ & $39(40)$ & $34(35)$ & $27(28)$ \\
\hline
\end{tabular}




\begin{tabular}{|c|c|c|c|}
\hline & $\begin{array}{l}\text { "Core" parallel } \\
\text { charts }\end{array}$ & $\begin{array}{c}\text { “Contingent" parallel } \\
\text { charts }\end{array}$ & $\begin{array}{l}\text { "Moral" parallel } \\
\text { charts }\end{array}$ \\
\hline Charts & 150 & 153 & 59 \\
\hline \multicolumn{4}{|l|}{ Characters n } \\
\hline$\leqslant 1000$ & $1(2)$ & $24(36)$ & $10(6)$ \\
\hline $1001-2000$ & $31(43)$ & $50(76)$ & 39 (23) \\
\hline $2001-3000$ & $31(43)$ & $20(30)$ & $22(13)$ \\
\hline$>3000$ & $36(54)$ & $7(11)$ & $29(17)$ \\
\hline \multicolumn{4}{|c|}{ Time spent writing min } \\
\hline$<30$ & $28(27)$ & $54(71)$ & $33(15)$ \\
\hline $30-60$ & $33(44)$ & $23(30)$ & $30(14)$ \\
\hline$>60$ & 39 (52) & $23(31)$ & $37(17)$ \\
\hline
\end{tabular}

The factors influencing the relationship (table 4) seem to be smoking and the emotions felt by patients at the beginning, as perceived by clinicians: particularly negative influencers seemed to be the emotions of anger, denial, shame and submission. These data show no relevant difference between the patients described in "core" and "contingent" narratives, whereas in "moral" narratives these factors are more significant. At the beginning of the narrative, $92 \%$ of the pulmonologists reported that their patients experienced limitations in their physical activities and that they felt that COPD was comparable to a limit, a grief, a prison ("I'm imprisoned inside a bubble of air without windows") or a shame ("I believe the patient is ashamed of his illness"), while $20 \%$ of patients denied having COPD at the first visit. They described a very different range of activities, from work to fishing, from sports to being a grandparent, but

TABLE 4 Personal details of the patients described in the parallel charts and their influence on the narrative style

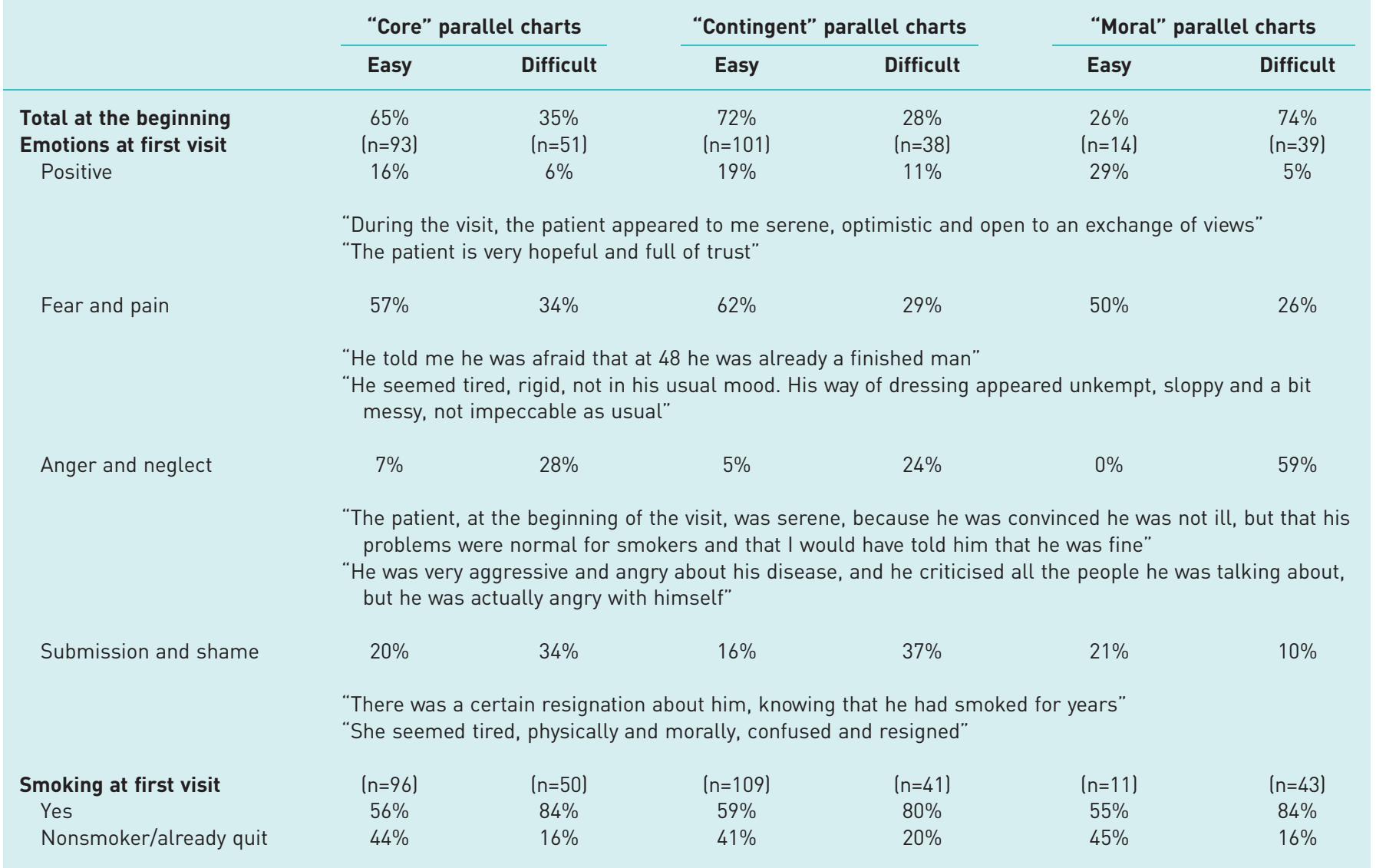


also the impact of COPD on their social life, such as going out with friends, walking, going to the theatre or even talking ("The patient told me that he began to understand his illness when he had to stop going to pick mushrooms and going fishing, and the dyspnoea did not allow him to take two consecutive steps ..."; "She enrolled in a water aerobics course with her friends, but she could not do the same things they did. Her embarrassment drove her to stop any physical activity, especially in the company of other people, due to a deep sense of shame").

Easy relationships did not change, regardless of the narrative style; however, physicians who wrote "core" parallel charts were more inclined to make difficult relationships evolve into positive relationships (94\%) compared with those who wrote "contingent" (62\%) or "moral" (46\%) narratives.

As summarised in table 5, there are a few factors that differ between difficult relationships and easy or evolving relationships. First, the choice of a specific therapy seems to be more effective if it is influenced by the patient's life and explained with simple words ("illness-oriented").

Even the emotions felt by pulmonologists after communication of the therapy change can predict the failure of a relationship, in particular when the physician felt anger and discomfort. In this case, we also observed a slight difference in the physicians who wrote "contingent" narratives, as they experience a higher sense of duty and responsibility.

Smoking cessation strategies differ, depending on the "core", "contingent" or "moral" attitude of the pulmonologist: the first preferred a more comprehensive approach, through counselling and compromise, whereas in "contingent" and "moral" narratives physicians used threats and reprimands.

According to the perceptions of the pulmonologists, the majority of difficult patients experienced the proposed therapy negatively, while $>30 \%$ of the other patients experienced it even as a liberation, the beginning of a new life (table 6).

Positive relationships also impacted on the resumption of activities; only in difficult relationships did the patient not experience a recovery. In some cases, although they still experienced limitations due to COPD (e.g. climbing stairs, doing intense physical activity or lifting heavy weights), patients learned to cope with them and to not be ashamed of their situation.

Pulmonologists were satisfied with these results and, thinking back to the path of care, just a few of them considered it difficult, while the others had the chance to think and identify new areas for improvement, as well as the key role of attentive listening to the patient.

\section{Efficacy of the education project perceived by pulmonologists}

After writing parallel charts, clinicians stated that they had learned through this educational project to be perseverant, to better understand the importance of some aspects of the disease, but mostly they understood the importance of listening to every single patient and trying to identify those little things in their life capable of motivating them individually (table 7).

In conclusion, the educational project was effective, and almost all participants stated that the narrative medicine approach influenced their practice and their attitude towards the patient (table 8). In particular, only $6 \%$ of pulmonologists experienced difficulties in writing, while the others declared that it was beneficial and liberating, a moment to reflect and a way to be a more complete physician.

\section{Discussion}

Overall, this narrative medicine education project was evaluated as positive by $95 \%$ of the participants, who stated that this new competence affected their daily practice and their approach to patients. Starting from their daily concrete experiences of dealing with patients, through the webinar and the newsletters on narrative medicine, physicians could add the reflective observation to their daily experience. Learning the use of the parallel chart was the abstract conceptualisation of Kolb's cycle [24], which brought pulmonologists to test narrative medicine in the last phase of the cycle, i.e. active experimentation, helping them to achieve the goal of improving the doctor-patient relationship.

Except for the few cases of pulmonologists who wrote "moral" narratives, the analysis of the parallel charts showed that physicians, when encouraged to reflect on their relationships with people with COPD by writing in a "core" language, experienced an overall improvement in the quality of care of their patients. The quality of care is not restricted to adherence and clinical outcomes; the narratives also highlighted improvements in the emotions perceived by physicians and their perception of patient's feelings. At the end of the "core" parallel charts", physicians felt hope and trust, and even if the improvements could be evaluated as minimal from the outside, pulmonologists reported that patients felt looked after, protected; they felt that someone had really taken care of them as whole persons, not just as patients. This positive 


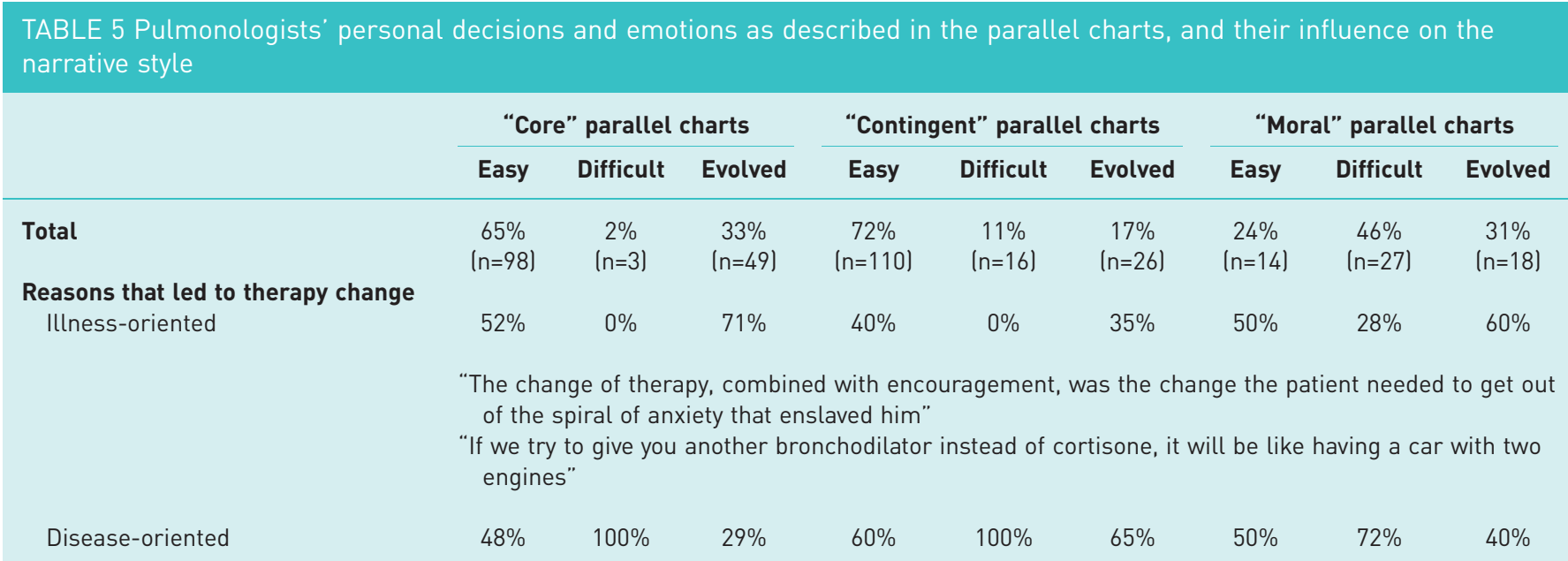

"A proper diagnosis through anamnesis and spirometry. Therefore, initiated therapy recommended by the international COPD guidelines"

"I explained to him that, after seeing the spirometry results, he could not fail to follow my advice and that I would facilitate his tasks with a simpler, but still effective therapy"

\section{Physicians' emotions after communication of therapy change} Satisfaction and trust

Anger and discomfort

Duty and responsibility

\section{Smoking cessation strategies}

Reprimands

Compromise

Counselling
$55 \%$

$33 \%$

$37 \%$

$51 \%$

$15 \%$

$24 \%$

$55 \%$

$19 \%$

$8 \%$

"I felt happy seeing that in a few minutes the husband, in front of the opportunity to modify a therapy that was not objectively optimal, returned to smile, with a much less concerned expression"
$5 \%$
$67 \%$
$37 \%$
$3 \%$
$62 \%$
$14 \%$
$27 \%$
$5 \%$
$46 \%$

"I felt the patient distant and unwilling to follow the directions given, especially for what concerns the behavioural changes. It seemed that she did not care about her health"

"Almost helpless ... I thought it was a failure"

$\begin{array}{llllllll}40 \% & 0 \% & 37 \% & 46 \% \% & 23 \% & 62 \% & 18 \% & 76 \%\end{array}$

"I felt I was responsible for his happiness"

"I felt obliged to help him and make him change his mind"

$\begin{array}{llllllll}24 \% & 100 \% & 35 \% & 67 \% & 75 \% & 54 \% & 80 \% & 90 \%\end{array}$

"I ask him if he still smokes and he answers yes. AT THIS POINT, I burst out and I rebuke him because he KEPT SMOKING. I added that it's not right that I and others have to sustain healthcare expenditure while he continues to be addicted to nicotine"

$\begin{array}{llllllll}57 \% & 0 \% & 48 \% & 27 \% & 25 \% & 38 \% & 20 \% & 10 \%\end{array}$

"I also took the opportunity to remind her of the damage of cigarette smoke and how she had been good recently, in reducing the daily number of cigarettes"
$19 \%$
$0 \%$
$17 \%$
$7 \%$
$0 \%$
$8 \%$
$0 \%$
$0 \%$
$0 \%$

"During my next visit, I tried to make the patient feel at ease, in order to better understand the stressful situations that led her to her compulsive desire of smoking"

COPD: chronic obstructive pulmonary disease.

effect reverberated throughout the spirit of the physicians, who regained passion for their work, feeling more complete.

Reflective writing and the narrative medicine approach was shown to help clinicians to establish empathic relationships [32]. It has already been included in several medical school training curricula, 
TABLE 6 Results of healthcare relationships in terms of therapy, activities resumed, pathway of care and adherence, their correlation to the narrative style, and the type of relationship established

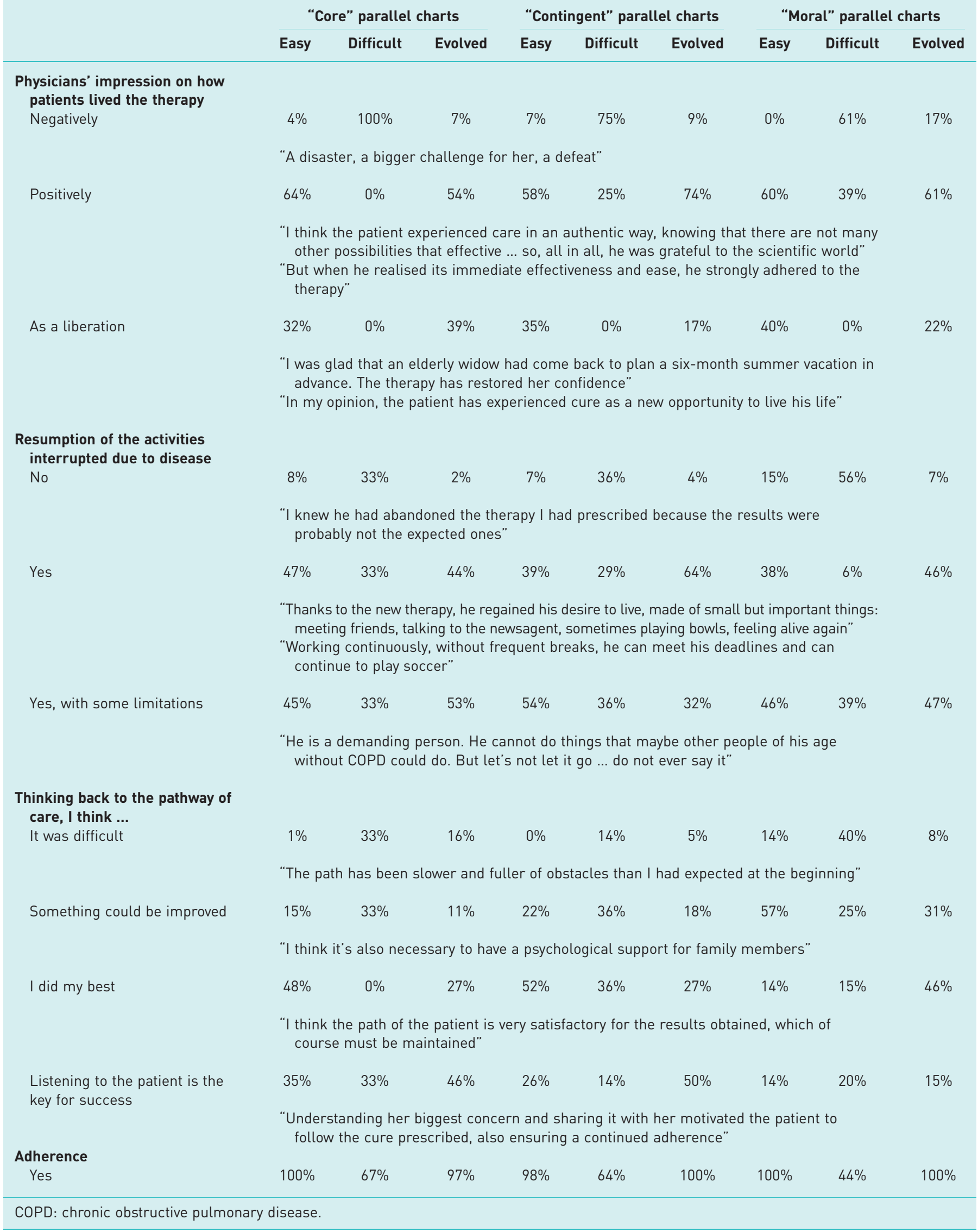




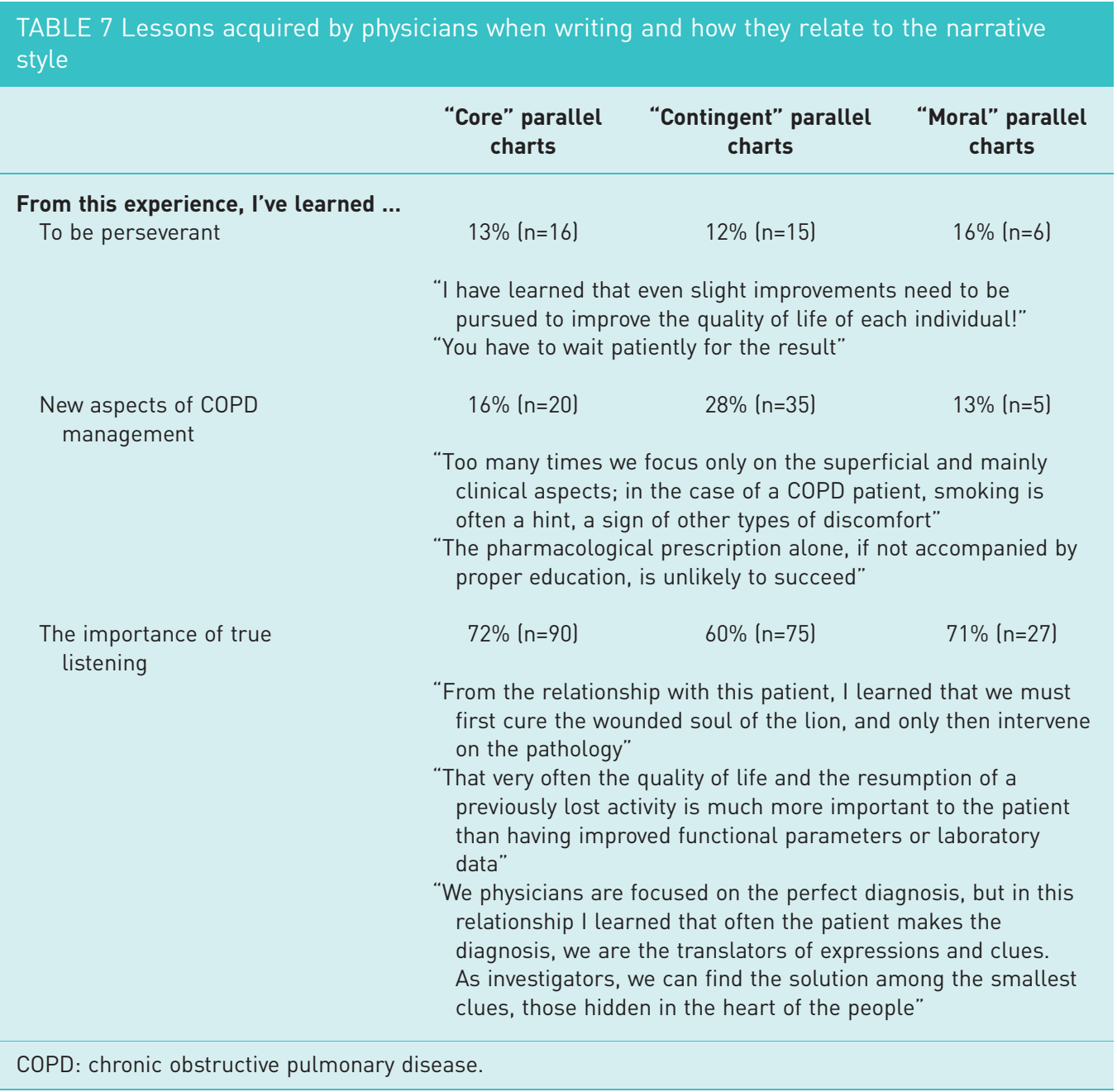

resulting in significant improvements in physicians' clinical practice [33]. This writing, which differs from the classical clinical record, requires an open mind, time and practice. This means that it would sometimes be difficult to use the parallel chart in daily practice and for all patients, but this tool could be a resource when pulmonologists have to deal with difficult cases. However, the verbal narrative medicine approach is not difficult to apply in daily practice through attentive listening, the use of appropriate language and the search for an empathic relationship [34, 35]. In addition, through close reading of the narratives written by both physicians and patients, pulmonologists can improve their approach and their empathic skills [36].

One issue that remains open is the future possibility of bringing together the medical records and the parallel charts in a single document. Rita Charon created the parallel chart as a private document, a sort of intimate diary that can be shared with patients or colleagues, depending on the will of its writer [21]. In recent years, however, a growing number of experts have stated that physicians' narratives should be an integral part of the clinical record [37], such that patient's narratives start to be compared with clinical outcomes [38].

In conclusion, this educational project showed the positive effect on daily practice of the narrative medicine approach, which, despite the difficulties in adopting it in our healthcare system, demonstrated that positive relationships based on listening and understanding can help patients be more adherent to treatment, improve their lifestyle, resume activities interrupted because of their failing health and improve their quality of life. The notable result is that only $4 \mathrm{~h}$ of training, consisting of a 2 -h online lesson and follow-up newsletters, was effective in achieving improvements in the doctor-patient relationship. This project has been carried out on COPD, but the narrative medicine approach can be applied to all chronic and degenerative diseases [39], where the goal of establishing a good relationship with the patient becomes of fundamental importance to achieve good health outcomes. 


\section{TABLE 8 Appreciation of the educational project in relationship to the narrative style}

"Core" parallel charts

\section{“Contingent" parallel} charts
“Moral" parallel charts

\section{The project influenced my daily practice}

Yes, partially or entirely

$85 \%(n=113)$

$83 \%(n=112)$

$60 \%(n=28)$

"This approach has greatly improved my relationship with patients, making me understand that empathy associated with drug therapy can be useful in treating not only the disease but also the person"

"Yes! I am more confident about the good performance of my prescriptions"

No

$$
0 \%(n=0)
$$

$5 \%(n=7)$

$17 \%(n=8)$

"I'm not used to writing parallel charts. I don't know how to describe my feelings, I honestly don't really like it"

I already applied this approach

$$
15 \%(n=20)
$$$$
12 \%(n=16)
$$$$
23 \%(n=11)
$$

"I like to think of my patients not just as clinical cases, I think I do this every day. Sure, writing is another thing, but I'm still motivated"

\section{Writing the parallel chart ...}

Was beneficial and liberating

Made me reflect

Made me feel complete

Was demanding

$38 \%(n=43)$

$12 \%(n=15)$

$38 \%(n=12)$

"It was liberating, almost therapeutic"

"Satisfied and accomplished"

"Interested in applying a methodology that I have not used to date"

"The narration has put me at the patient level, a parallel level, but with meeting points. It does not exist in geometry but in reality, it does!"

$$
33 \%(n=38)
$$$$
31 \%(n=39)
$$$$
13 \%(n=4)
$$

"By concentrating on the patient's experience, the doctor is obliged to expose himself as a person, sympathetic with the subject visited, because he is subject to the same psycho-social and affective dynamics"

"It caused me not to run, but to think and rethink, he brought back the focus on the man, rather than on the patient"

$$
23 \%(n=26)
$$$$
10 \%(n=13)
$$$$
38 \%(n=12)
$$

"A useful moment of reflection. Often in the hospital you feel a machine that has to "crunch" visits. Thanks to writing the parallel charts I felt human once again"

"I felt helpful and positive, happy with my work and the relationship I can build with several patients. Watching such situations makes us realise how important the emotional aspects of our profession are and I hope that other colleagues who are less interested in this aspect will see the improvements that this approach can make to people's lifes"

$$
6 \%(n=7)
$$$$
5 \%(n=6)
$$$$
13 \%(n=4)
$$

"I have struggled a bit to detach myself from the scientific methodology l'd been using for years, but it was a great challenge and I hope I can do a decent job"

Acknowledgements: The authors are grateful to all the pulmonologists of the Words of Breath Group: Anna Annunziata Sabrina Arondi, Sara Balestracci, Elena Bargagli, Angelo Bastianelli, Michele Battilana, Maria Grazia Boi, Bassal Boulos, Luisa Brussino, Guglielmo Bussoli, Biagio Campana, Silvia Capato, Chiara Carraro, Francesco Carrozzi, Maria 
Antonietta Ceccon, Franco Chiaravalloti, Mongiardi Christian, Ida Ciamarra, Antonello Colangeli, Claudia Coli, Paola Contini, Eugenio Cosentino, Nicola Costanzo, Emilio De Angelis, Francesca De Filippis, Nicola De Rosa, Ginevra Del Giudice, Felice Di Perna, Bledar Elezi, Varzaneh ShoKoofoe Eslami, Giorgio Ferraro, Maria Concetta Giofrè, Francesca Giovannelli, Simona Guerra, Giuseppe La Fauci, Claudia Madaschi, Ennio Mantellini, Silvia Marani, Rita Marchi, Al Asghar Masoudì, Claudio Mastruzzo, Emilio Melica, Filomena Minicozzi, Aldo Miraglia, Antonio Molino, Maria Adelaide Moschella, Massimiliano Napolitano, Patrizia Palmulli, Alberto Pavan, Andrea Pelucchi, Antonio Perciaccante, Vincenzo Pezzella, Vittorio Pietrangeli, Biagio Polla, Maurizio Rizzi, Javier Rosada, Sandro Rossi, Maurizio Russo, Giancarlo Santanocto, Giorgio Scarmagnan, Fabio Scotto, Ernesto Serpe, Manuela Serpilli, Maria Serra, Maria Serravillo, Danilo Taccaliti, Chiara Ticozzi, Aniello Tinto, Nello Tobia, Victoria Tourchenko, Andrea Turati, Paolo Vivoli and Erika Zanardi.

Conflict of interest: A. Cappuccio, S. Napolitano and M.G. Marini report grants from Novartis Farma Italia, during the conduct of the study.

Support statement: The authors would like to thank Novartis Farma Italia, which commissioned this project to the ISTUD Foundation and provided financial support.

\section{References}

1 Sin DD, Anthonisen NR, Soriano JB, et al. Mortality in COPD: role of comorbidities. Eur Respir J 2006; 28 : $1245-1251$

2 Global Initiative for Chronic Obstructive Lung Disease. Global Strategy for the Diagnosis, Management, and Prevention of Chronic Obstructive Pulmonary Disease. 2017. http://goldcopd.org/gold-2017-global-strategydiagnosis-management-prevention-copd/ Date last accessed: March 30, 2018.

3 Stang P, Lydick E, Silberman C, et al. The prevalence of COPD: using smoking rates to estimate disease frequency in the general population. Chest 2000; 117: 5 Suppl. 2, 354S-359S.

4 Dal Negro R, Rossi A, Cerveri I. The burden of COPD in Italy: results from the Confronting COPD survey. Respir Med 2003; 97: Suppl. C, S43-S50.

$5 \quad$ Nazir SA, Erbland ML. Chronic obstructive pulmonary disease. Drugs Aging 2009; 26: 813-831.

6 Pauwels RA, Rabe KF. Burden and clinical features of chronic obstructive pulmonary disease (COPD). Lancet 2004; 364: 613-620.

7 Lusuardi M, Lucioni C, De Benedetto F, et al. GOLD severity stratification and risk of hospitalisation for COPD exacerbations. Monaldi Arch Chest Dis 2008; 69: 164-169.

8 Sanduzzi A, Balbo P, Candoli P, et al. COPD: adherence to therapy. Multidiscip Respir Med 2014; 9: 60

9 Lyna P, McBride C, Samsa G, et al. Exploring the association between perceived risks of smoking and benefits to quitting: who does not see the link? Addict Behav 2002; 27: 293-307.

10 Han J, Dai L, Zhong N, et al. Breathlessness or health status in chronic obstructive pulmonary disease: the impact of different definitions. COPD 2015; 12: 115-125.

11 Carel H, Macnaughton J, Dodd J. Invisible suffering: breathlessness in and beyond the clinic. Lancet Respir Med 2015; 3: 278-279.

12 Vermeire P. The burden of chronic obstructive pulmonary disease. Respir Med 2002; 96: Suppl. C, S3-S10.

13 Pinnock H, Kendall M, Murray SA, et al. Living and dying with severe chronic obstructive pulmonary disease: multi-perspective longitudinal qualitative study. BMJ 2011; 342: d142.

14 Wong SS, Abdullah N, Abdullah A, et al. Unmet needs of patients with chronic obstructive pulmonary disease (COPD): a qualitative study on patients and doctors. BMC Fam Pract 2014; 15: 67.

15 Bourbeau J, Barlett SJ. Patient adherence in COPD. Thorax 2008; 63: 831-838.

16 Agh T, Inotai A, Meszaros A. Factors associated with medication adherence in patients with chronic obstructive pulmonary disease. Respiration 2011; 82: 328-334.

17 Blasi F, Raddi F, Miravitlles M. Interactive monitoring service and COPD: is it possible to reduce nonadherence? COPD 2015; 12: 227-233.

18 Harb N, Foster JM, Dobler CC. Patient-perceived treatment burden of chronic obstructive pulmonary disease. Int J Chron Obstruct Pulmon Dis 2017; 12: 1641-1652.

19 Banfi P, Cappuccio A, Latella ME, et al. Narrative medicine to improve the management and quality of life of patients with COPD: the first experience applying parallel chart in Italy. Int J Chron Obstruct Pulmon Dis 2018; 13: $287-297$.

20 Greenhalgh T. Narrative based medicine: narrative based medicine in an evidence based world. BMJ 1999; 318: 323-325.

21 Marini MG. Narrative Medicine: Bridging the Gap between Evidence-Based Care and Medical Humanities. Cham, Springer, 2016.

22 Charon R. Narrative medicine in the international education of physicians. Presse Med 2013; 42: 3-5.

23 Ousager J, Johannessen H. Humanities in undergraduate medical education: a literature review. Acad Med 2010; 85: 988-998.

24 Kolb DA. Experiential Learning: Experience as the Source of Learning and Development. Englewood Cliffs, Prentice-Hall, 1984.

25 Marini MG, Reale L, Cappuccio A, et al. Narrative medicine to highlight values of Italian pain therapists in a changing healthcare system. Pain Manag 2014; 4: 351-362.

26 Greenhalgh T. Cultural Contexts of Health: The Use of Narrative Research in the Health Sector (Health Evidence Network Synthesis Report 49). Copenhagen, WHO Regional Office for Europe, 2016.

27 Glaser BG, Strauss AL, Strutzel E. The discovery of grounded theory; strategies for qualitative research. Nurs Res 1968; 17: 364.

28 Duque RL. Review: Catherine Kohler Riessman (2008). Narrative Methods for the Human Sciences. Forum Qual Social Res 2009; 11: 19.

29 Kleinman A. The Illness Narrative, Suffering, Healing and The Human Condition. New York, Basic Books, 1989.

30 Bury M. Illness narratives: fact or fiction? Sociol Health Illness 2001; 23: 263-285. 
31 Eurostat Statistics Explained. Healthcare personnel statistics - physicians. 2017. http://ec.europa.eu/eurostat/ statistics-explained/index.php/Healthcare_personnel_statistics_-_physicians Date last accessed: April 11, 2018.

32 DasGupta S, Charon R. Personal illness narratives: using reflective writing to teach empathy. Acad Med 2004; 79: 351-356.

33 Chen I, Forbes C. Reflective writing and its impact on empathy in medical education: systematic review. J Educ Eval Health Prof 2014; 11: 20.

34 Kvangarsnes $\mathrm{M}$, Torheim $\mathrm{H}$, Hole $\mathrm{T}$, et al. Narratives of breathlessness in chronic obstructive pulmonary disease. J Clin Nurs 2013; 22: 3062-3070.

35 Langewitz W, Denz M, Keller A, et al. Spontaneous talking time at start of consultation in outpatient clinic: cohort study. BMJ 2002; 325: 682-683.

36 Charon R, Hermann N, Devlin MJ. Close reading and creative writing in clinical education: teaching attention, representation, and affiliation. Acad Med 2016; 91: 345-350.

37 Robey T. The art of writing patient record notes. Virtual Mentor 2011; 13: 482-484.

38 Malcolm D, Orme MW, Morgan MD, et al. Chronic obstructive pulmonary disease (COPD), ilness narratives and Elias's sociology of knowledge. Soc Sci Med 2017; 192: 58-65.

39 Gargiulo G, Sansone V, Rea T, et al. Narrative Based Medicine as a tool for needs assessment of patients undergoing hematopoietic stem cell transplantation. Acta Biomed 2017; 88: 18-24. 